\title{
Linking SEDIMENT Transport AND STRATIGRAPHY ON THE CONTINENTAL SHELF
}

By Patricia L. Wiberg, David A. Cacchione, Richard W. Sternberg and L. Donelson Wright
$\mathrm{T}$ HE GOAL OF THE SHELF sediment dynamics component of STRATAFORM is to link sediment transport processes active on the continental shelf to the formation and preservation of event beds in shelf sediment deposits. An approach combining shelf sediment-transport models with high-resolution measurements of water-column and bed properties over periods from several months to several years allows us to make quantitative estimates of bed modification caused by sediment resuspension during episodic transport events. These modifications include erosion and deposition of bed material, formation of graded storm beds, and changes in small-scale bed surface morphology. The characteristics of the resulting "event bed" (thickness, grading, physical structures) are a function of flow and bed properties, depending on both temporal and spatial variations in sediment transport.

Sediment transport on the continental shelf depends on surface-wave conditions, bottom-boundary-layer currents, fluid stratification, and bed characteristics. including grain size, density, porosity, and surface roughness. In general, sediment transport rates and depths of bed reworking are greatest when large, long-period waves occur simultaneously with strong, persistent currents. Thus understanding the magnitude and frequency of transport requires knowledge of the wave and current conditions on the shelf over sufficiently long periods of time to develop statistical characterizations of the wave and current fields and to document the resulting resuspension and bed modification. This information also provides critical

P.L. Wiberg. Dept. of Environmental Sciences. University of Virginia, Charlottesville. VA 22903. USA: D.A. Cacchione. U.S. Geological Survey, 345 Middlefield Rd.. Menlo Park, CA 94025, USA; R.W. Sternberg. School of Oceanography. University of Washington, Seatlle, WA 98195, USA: L.D. Wright, Virginia Institute of Marine Science, College of William and Mary, Gloucester Point, VA 23062, USA. input to, and tests of, shelf sediment-transport models that can be used to examine transport patterns over longer time scales and broader spatial scales. Toward this end, a field and modeling program has been initiated to examine transport processes on the shelf at the STRATAFORM site on the northern California, Eel shelf.

\section{Observational Approach}

Bottom-boundary-layer measurements of the response of sediment on the bed and in suspension to oceanographic forcing provide direct information on sediment movement under the influence of waves and currents at strategic locations within the transport pathway. A prominent feature of the Eel shelf is a mid-and outer-shelf silt deposit produced in part by deposition associated with floods on the Eel River. The silt deposit grades into sand at the inner-shelf boundary of the deposit (between 50 and $60 \mathrm{~m}$ water depth), resulting in a region of sediment mixing where bottom sediment textures, sedimentary structures, and morphology alter and develop in response to changing wave and current velocities, up- and downwelling conditions, pycnocline strength, and variations in sediment supply by the river.

To characterize transport processes and bed response at this critical facies boundary, long-term measurements at one site and shorter-term intensive measurements at several sites have been undertaken using bottom-mounted instrument systems. Long-term measurements at $60-\mathrm{m}$ water depth along the $S$ sampling transect (site $S 60$, $40-53.3 \mathrm{~N}, 124-15.3 \mathrm{~W}$ ) (Nittrouer and Kravitz, 1996, this issue) began in September 1995, and will continue for a minimum of $3 \mathrm{y}$. Intensive measurements of the bottom boundary layer and seabed were made during the winter storm season of 1995-1996 (December-March). These measurements were made along a cross-shelf transect comprising a 50-m-deep inner-shelf site on a silty-sand bed. a 60-m-deep site in the sand/silt transition
... to link sediment

transport processes

active on the conti-

nental shelf to the

formation and

preservation of event

beds. . 
A plan of rapid-re-

sponse seabed sam-

pling . . . makes it

possible to relate

measured transport

to observed bed

modification. zone, and a 70-m site within the silt deposit. Each bottom system records wave velocities, current and suspended-sediment-concentration profiles. temperature, salinity, and bottom elevation. Simultaneous measurements along this transect allow us to examine the dependence of transport on substrate type, variations in seabed response, correlation of net deposition and erosion among sites. and cross-shelf divergences in near-bed flow and transport. A plan of rapid-response seabed sampling following a large transport event, in addition to the ongoing monitoring of seabed characteristics over the shelf, makes it possible to relate measured transport to observed bed modification.

Seabed properties along the cross-shelf transect range from sandy, rippled beds on the inner-shelf to silty, bioturbated beds on the mid-shelf. These changes in sediment texture and surface morphology across the transect, as well as changes at each site during transport events, affect bed roughness, and hence near-bed flow and shear stress, threshold of sediment motion, and preserved sedimentary structures. To understand these changes in bottom roughness, the intensive field experiment includes seabed surface and subsurface imaging, quantitative characterization of bottom roughness scales. and detailed analysis of core samples.

\section{Observational Results}

Some results from the first deployment period at the monitoring site (S60) 21 September 1995 to 10 November 1995, are shown in Figure 1. The top panel presents current speed 1.0 meter above the seabed (mab), which varies from 0 to $30 \mathrm{~cm}$ $\mathrm{s}^{-1}$. The middle panel shows the bottom wave orbital velocities calculated for $60-\mathrm{m}$ water depth from surface-wave spectra measured by National

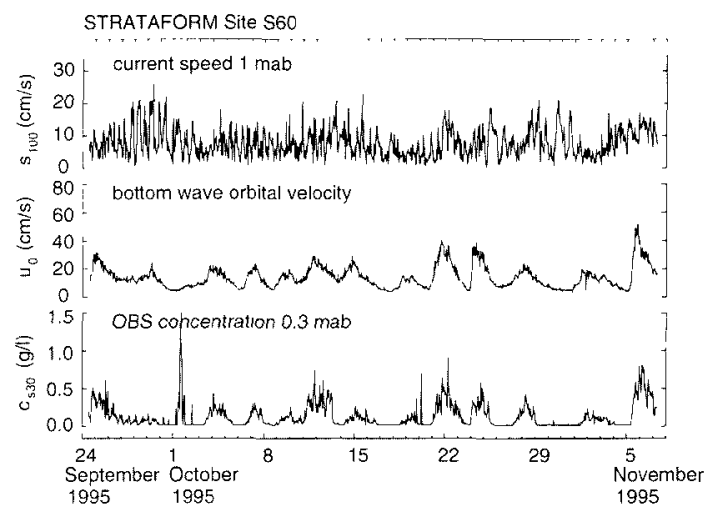

Fig. 1: Measured time series of current speed 1.0 m abole the seabed (mab) (top panel). bottom nave-orbital velocity (middle panel), and suspended-sediment concentration 0.3 nab measured by the extended-duration tripod at site $S 60(60-\mathrm{m}$ water depth). The good correlation between high bottom-wave velocities and high suspended-sediment concentrations suggests resuspension by high bottom stresses.
Data Buoy Center (NDBC) Buoy 46022 on the Eel margin: these values correlate very well with pressure variance calculated for each burst from the tripod data. The bottom panel has the hourly suspended-sediment concentration $0.3 \mathrm{mab}$, which ranges from zero to $>\mathrm{l} \mathrm{g} \mathrm{l}^{-1}$ over the selected data record.

The time series of suspended-sediment concentration illustrates the energetic nature of the Eel continental shelf and the significant sediment response. Over the first 45 -day record, 13 identifiable sediment suspension or transport events occurred, each lasting an average of $\sim 2$ days. Additionally, the data show a strong correlation between bottom wave velocities and suspendedsediment concentrations. The only exception is the brief high-concentration event on 1 October. During this time measurements by an optical backscatter sensor (OBS) 1 mab indicate no sediment in suspension, suggesting that something may have temporarily blocked the lower ( $0.3 \mathrm{mab})$ OBS sensor resulting in spurious high values.

The observed correlation between surface-wave action and bottom-sediment resuspension events is consistent with observations from a number of other shelf settings (e.g., Drake and Cacchione, 1985; Cacchione and Drake. 1990; Lyne et al., 1990; Sherwood et al.. 1994) where large surface waves are required to produce values of bottom stress large enough to initiate transport. In these locations, the coincident bottom-boundary-layer currents govern the distribution of the sediment in the water column and the speed and direction of transport. During the period of this initial 45-day record, discharges from the Eel River were uniformly low, with an average value of $5.8 \mathrm{~m}^{3} \mathrm{~s}^{-1}$ and a maximum value of $7.8 \mathrm{~m}^{3} \mathrm{~s}$.

As part of the intensive cross-shelf deployment of bottom tripods, the U.S. Geological Survey (USGS) GEOPROBE tripod (Cacchione and Drake, 1990) was deployed at 52-m water depth along the S sampling line (site S50, 40-53.0N, 124-13.9W) on 7 December 1995 and recovered on 8 January 1996. The tripod was then redeployed at the same site as part of the cross-shelf transect of bottom measurements made during January-March 1996. An energetic storm passed through the region during 10-13 December 1995. NDBC Buoy 46022 recorded sustained. southerly to southeasterly winds in excess of 40 knots and waves $>10 \mathrm{~m}$ during this storm. The tripod data shown in Figure 2 demonstrate the large wave and current velocities on the inner shelf associated with this storm. The top two panels in Figure 2 show hourly averaged current vectors and significant bottom wave speeds at the uppermost sensor $(\sim 1.2 \mathrm{~m}$ above the bottom) over an 8-day period including the storm. Currents during the storm were consistently from the southsoutheast and reached maximum speeds of $\sim 65 \mathrm{~cm}$ $\mathrm{s}^{-1}$ on 12 December. Near-bottom wave speeds 


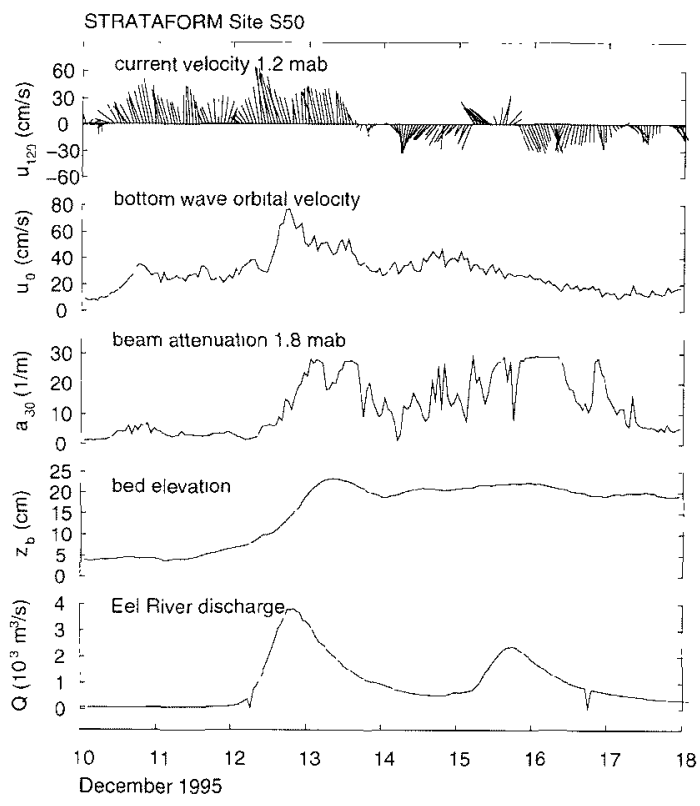

Fig. 2: Measured time series of current velocity $1.2 \mathrm{~m}$ above the seabed (mab) (top panel; alongshelf flow corresponds to a vertical vector). bottom wave-orbital velocity (2nd panel), beam attenuation measured 1.8 mab (3rd panel), and bed elevation (4th panel) measured by the GEOPROBE at site S5O (50-m water depth) during a storm in mid-December 1995. Water discharge from the Eel River is shown in the bottom panel. Maximum suspended-sediment concentration lags behind peak bottom wave velocity during this storm, suggesting that sediment advecting past the tripod is contributing to the measured turbidity. Sediment introduced to the shelf during the Eel River floods shown in the bottom panel could be the source of the advected sediment.

were $\sim 80 \mathrm{~cm} \mathrm{~s}^{-1}$ during the peak of the storm on 12 December, with instantaneous recorded speeds in excess of $110 \mathrm{~cm} \mathrm{~s}^{-1}$. Maximum wave speeds lag the peak average currents by $\sim 4 \mathrm{~h}$.

Beam attenuation determined from one of three light-emitting diode transmissometers mounted on the tripod achieved maximum saturation values ( $\sim 30$ attenuation units) several times during the 8day period (Fig. 2). The highest values of beam attenuation, and therefore turbidity, during the storm occurred early on 13 December $\sim 12 \mathrm{~h}$ after the peak wave speeds. This lag in highest concentrations of suspended sediment relative to peak wave conditions suggests that the materials causing the highest values of turbidity were advected into the tripod location rather than resuspended by high wave-induced stresses. In fact, on 16 December a prolonged period of high turbidity occurs during waning near-bottom wave velocities. This relationship suggests that although some local resuspension of bottom sediment would be caused by large wave stresses (note the rise in beam at- tenuation at about 1600 on 12 December). advection of suspended materials from other locations to the tripod site dominates the measured turbidity during this period.

Further indirect evidence for an advected sediment component to the beam attenuation record comes from the discharge record for the Eel River. The hourly record of discharge from the USGS gauging station on the Eel River at Scotia, CA, during the December storm is shown in the bottom panel of Figure 2. Discharge peaked twice during this 8-day period. reaching a maximum of $3.8 \times 10^{3} \mathrm{~m}^{3} \mathrm{~s}^{-1}$. Discharge was also high on the Mad River to the north of the deployment sites. USGS sediment discharge measurements for the Eel River at comparable winter river discharge levels indicate suspended-sediment concentrations in the river would be on the order of $1-10 \mathrm{~g} \mathrm{l}^{-1}$ during these floods (Wheatcroft et al., 1997). Large pulses of riverine sediment introduced to the shelf during the December storm may account for the large sediment concentrations recorded by the GEOPROBE in the absence of large waves, e.g., 15-16 December 1995.

A notable feature of the December storm at the GEOPROBE site (S50) is the large and rather rapid apparent rise in bed elevation as determined from the measurements of the sonic altimeter (Fig. 2). Although this change in apparent bed elevation coincides with a period of high river discharge. deposition of river-derived material is not likely to account for a change in bed elevation of this magnitude $(15-20 \mathrm{~cm})$. Detailed measurements following a much larger flood event on the Eel River in January 1995 reveal a flood deposit on the shelf with a maximum thickness of $8.5 \mathrm{~cm}$ (Wheatcroft et al., 1996, this issue). The bed shear stresses during the nearly coincident peak wave and current conditions at the $50-\mathrm{m}$ site are large enough to transport fine sand as bedload. Thus, one interpretation of the apparent rise in bed elevation is that a sand wave migrated into the measurement zone of the tripod. Alternatively, the altimeter could be sensitive to high near-bed sediment concentrations.

Measurements of small-scale surface roughness elements and of the characteristics of the uppermost $10-20 \mathrm{~cm}$ of the bed, including sediment texture and physical and biogenic structures, before and after a transport event such as the one shown in Figure 2, are being collected to document processes such as bed reworking and bedform migration (Wheatcroft et al., 1996, this issue). These observations provide the link between the water-column processes measured by the bottom tripods and the formation and characteristics of event beds that may ultimately be incorporated into the sedimentary record.

\section{Modeling Approach}

A direct relationship between sediment-transport processes active on modern continental
. . materials caus-

ing the highest val-

ues of turbidity were

advected into the tri-

pod location rather

than resuspended. . 
. . . it is necessary

to characterize sedi-

ment transport and

bed reworking over

as long a time scale

as possible... shelves and the resultant fine-scale stratigraphy can be made using process-based bottom-boundary-layer flow and sediment-transport models that account for changes in bed sediment-size distributions and small-scale bed morphology over the course of transport events. A one-dimensional shelf transport model incorporating these bed-related processes has been shown to compare well with water-column measurements of flow and resuspension at other sites on the northern and southern California shelf (e.g., Wiberg et al., 1994). However, the STRATAFORM bed-sampling studies provide the first direct measurements of bed characteristics before and after measured resuspension events to test aspects of the model important to strata formation, including event-bed thickness, grading, and sedimentary structures at sandy and silty sites.

One of the advantages of coupling a modeling study with a field study of shelf sediment transport and event-bed formation is that the model can be used to examine patterns of transport and bed modification over considerably larger temporal and spatial scales than generally are resolved in a field study, provided the necessary model inputs can be specified. As input, the model requires near-bottom wave speeds, current velocity at some level in the bottom boundary layer, and bed sediment characteristics. Largely because of the limited duration of most shelf studies, the resuspension events captured in existing field data are typically representative of transport events with 1-2 y recurrence times. To make the link to stratigraphy, it is necessary to characterize sediment transport and bed reworking over as long a time scale as possible to include the widest possible range of transport events.

The extended duration observations on the shelf will provide $>3$ y of measured waves, currents, and resuspension. To estimate transport over longer time scales, the shelf transport model is being used in conjunction with hourly measurements of surface-wave spectra on the Eel margin recorded by NDBC wave buoys since 1982 . These data provide the information necessary to obtain a nearly $15-y$ record of bottom wave characteristics (orbital velocity and period) across the whole Eel shelf. Wave-driven transport events can be identified in these time series using threshold wave-velocity criteria developed from bottom tripod data like those in Figure 1. This approach yields a set of transport events large enough to begin to make statistical characterizations of important factors, including peak orbital velocity versus return period and the frequency and duration of wave-driven resuspension events, at different depths across the shelf and slope. Figure 3 shows the cross-shelf distribution of near-bottom wave speeds computed from NDBC Buoy 46022 during the December 1995 storm. Values of near-bed orbital velocity in the range of 10-20 $\mathrm{cm} \mathrm{s}^{-1}$ are generally sufficient

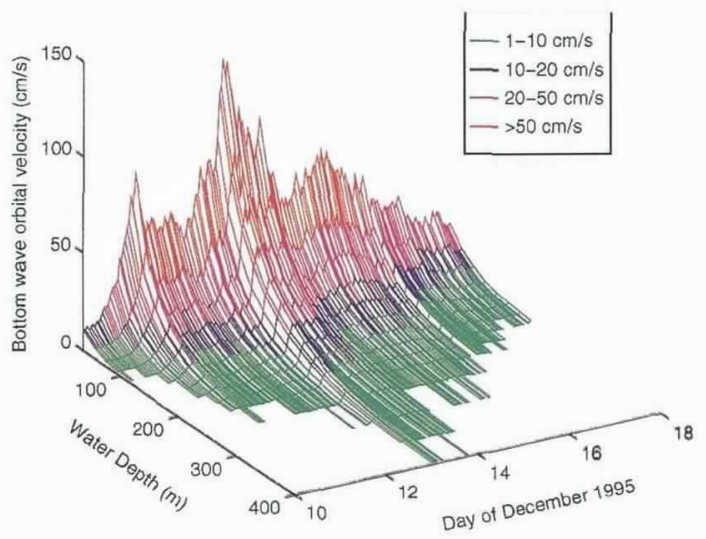

Fig. 3: Bottom wave-orbital velocity during the December 1995 storm for depths on the Eel shelf ranging from the inner shelf $(30 \mathrm{~m})$ to the upper slope $(400 \mathrm{~m})$. Wave velocities were computed using surface-wave spectral data from NDBC Buoy 46022. Bottom wave velocities in the range of 10-20 $\mathrm{cm} \mathrm{s}^{-1}$ (blue band) generally are sufficient to resuspend the finer bed fractions on the shelf.

to resuspend the finer fractions of the bed surface sediments. The time series in Figure 3 illustrates the variability in the maximum depth of resuspension over the course of this storm.

\section{Future Work}

The prominence of the January 1995 flood deposit in the surficial sediments of the Eel shelf and the strong indication in the GEOPROBE record (Fig. 2) for advection of river-derived sediment during a period of simultaneously high river discharge, waves, and currents in December 1995 underscores the importance of flood events to transport and bed characteristics on the Eel shelf. A field and modeling study to characterize the dynamics of the river sediment plume and the delivery of sediment to the bottom boundary layer and bed is now beginning. The field component of this study will include a second winter deployment of bottom tripods at sites closer to the river mouth and arrayed along the axis of the present silt deposit on the shelf. In addition, the analysis of cross-shelf transport during the period of simultaneous near-bed measurements at S50, S60, and S70 during the winter of 1996 is underway.

The sediment deposited on the shelf as a result of the January 1995 Eel River flood is very finegrained (Wheatcroft et al., 1996, this issue). Near-bottom suspended-sediment concentrations reach several 10ths of a gram per liter during the typical resuspension events illustrated in Figure 1. In-situ suspended sediment samples collected 0.22 mab by the GEOPROBE during the December 1995 deployment, when beam-attenuation measurements at site S50 were high or off scale, range from $\sim 1-3 \mathrm{~g}^{-1}$ (D.E. Drake, personal communication). At these high concentrations, 


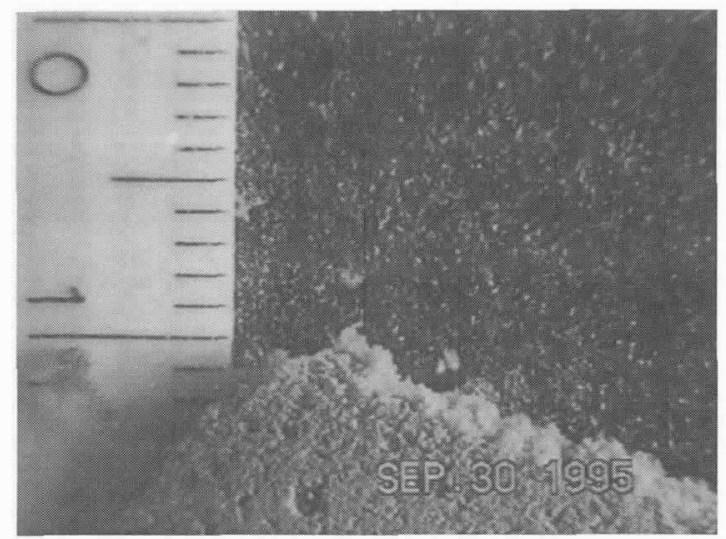

Fig. 4: Floc-camera image of flocculated particles in suspension and already deposited at site S60. The scale on the left of the image is in increments of $1 \mathrm{~mm}$.

fine-grained sediment should be flocculating to form larger aggregate particles in the water column, thereby significantly increasing the settling rate and decreasing the transport distance of the sediment. This possibility is supported by videocamera images (Sternberg et al., 1996) of floclike particles at the $60-\mathrm{m}$ extended-duration tripod site (Fig. 4). Floc-camera images and in-situ particle-size data from the extended-duration tripod on the Eel River shelf will provide data on particle characteristics over a range of resuspension and flood events with which to assess the importance of this process. In addition, the flocculation model of Hill and Nowell (1995) will be coupled to the shelf sediment-transport model to evaluate the effect of flocculation on the structure of suspended-sediment profiles and the agreement between calculated and measured suspended-sediment concentrations.

\section{Acknowledgements}

Funding for this research was provided by the Geology and Geophysics Program of the Office of Naval Research. The authors thank the many people who helped in the field, including George Tate, Joanne Thede, Rick Viall, Andrea Ogston, Bob Gammisch, Frank Farmer, and the crews of the Wecoma and Pacific Hunter. David Drake, Charles Nittrouer, and Joseph Kravitz provided helpful editorial comments on an earlier version of this paper. David Drake kindly provided GEOPROBE bag-sample concentrations for the December storm. Courtney Harris assisted with the wave analysis. Wave buoy data for the Eel margin were obtained from the NDBC world-wide web site at seaboard.ndbc.noaa.gov.

\section{References}

Cacchione, D.A. and D.E. Drake, 1990: Shelf sediment transport: an overview with applications to the northern California continental shelf. In: The Sea, vol. 9. B. Le Mehaute and D. Hanes, eds., John Wiley and Sons, New York, 729-773.

Drake, D.E. and D.A. Cacchione, 1985: Seasonal variation in sediment transport in the Russian River shelf, California. Cont. Shelf Res. 4, 495-514.

Hill, P.S. and A.R.M. Nowell, 1995: Comparison of two models of aggregation in continental-shelf bottom boundary layers. J. Geophys. Res. 100, 22, 749-763.

Lyne, V.D., B. Butman and W.D. Grant, 1990: Sediment movement along the U.S. east coast continental shelf II. Modelling suspended sediment concentration and transport during storms. Cont. Shelf Res., 10, 429-460.

Nittrouer, C.A. and J.H. Kravitz, 1996: STRATAFORM: a program to study the creation and interpretation of sedimentary strata on continental margins. Oceanography, 9, 146-152.

Sherwood, C.R., B. Butman, D.A. Cacchione, D.E. Drake, T.F Gross, R.W. Sternberg, P.L. Wiberg and A.J. Williams, III, 1994: Sediment-transport events on the northern California continental shelf during the 1990-1991 STRESS experiment. Cont. Shelf Res., 14, 1063-1099.

Sternberg, R.W., A. Ogston and R. Johnson: A video system for in-situ measurement of size and settling velocity of suspended particles, 1996. In: In Situ Measurements of Suspended Matter Particle Size and Settling Velocity. D. Eisma, ed. Netherlands J. Sea Res., Vol. 36, In press.

Wheatcroft, R.A., J.C. Borgeld, R.S. Born, D.E. Drake, E.L. Leithold, C.A. Nittrouer and C.K. Sommerfield, 1996: The anatomy of an oceanic flood deposit. Oceanography, 9, 158-162.

, C.K. Sommerfield, D.E. Drake, J.C. Borgeld and C.A. Nittrouer, 1997: Rapid and widespread dispersal of flood sediment on the northern California continental margin. Geology, Vol. 25, In press.

Wiberg, P.L., D.E. Drake and D.A. Cacchione, 1994: Sediment resuspension and bed armoring during high bottom stress events of the Northern California inner continental shelf: measurements and predictions. Cont. Shelf Res., 14, 1191-1219.
. . . fine-grained

sediment should be

flocculating to form

larger aggregate par-

ticles. . 